\title{
Use of endoscopic biopsy for diagnosing congestive gastropathy
}

\author{
C M CORBISHLEY,* S H SAVERYMUTTU, J D MAXWELL \\ From the Departments of *Histopathology and Medicine, St George's Hospital Medical School, London
}

SUMMARY The specificity of endoscopic biopsy specimens in diagnosing congestive gastropathy in 20 patients with portal hypertension, 20 patients with liver disease without portal hypertension, and 20 patients with a normal stomach at endoscopy without liver disease was examined. Histological assessment, which was performed without knowledge of the clinical details, showed changes previously reported to be indicative of congestive gastropathy in $9(47 \%)$ of patients with portal hypertension. Similar changes were also seen in $17(85 \%)$ of patients with liver disease without portal hypertension and in $16(84 \%)$ of patients with normal endoscopies without liver disease. These results show that the histological changes seen in endoscopic biopsy specimens of congestive gastropathy are not specific for this condition and therefore cannot be used to diagnose objectively the disease or assess management.

Mucosal and submucosal vascular changes have been described in gastric resection specimens from patients with portal hypertension and bleeding from haemorrhagic gastric lesions. The characteristic features were prominent capillary and venous dilatation in the absence of clinically important inflammation. ${ }^{1}$ The term congestive gastropathy has recently been introduced to describe the gastric mucosal changes in portal hypertension.'

Congestive gastropathy is a major clinical problem, accounting for between $10 \%$ and $50 \%$ of bleeds in patients with portal hypertension. ${ }^{1-4}$ It has been classified on the basis of endoscopic appearances into severe and mild categories. Severe congestive gastropathy is a well documented clinical condition, easily recognised endoscopically by discrete "cherry red spots" or a diffuse haemorrhagic gastritis usually associated with overt bleeding. ${ }^{\text {s } b}$ Mild congestive gastropathy, however, is less clearly defined clinically. The diagnosis is made endoscopically by identifying an abnormal mucosal appearance, but this approach is subjective and therefore liable to error. ${ }^{7}$

The accurate diagnosis of mild gastropathy is important for two reasons. Firstly, mild gastropathy may progress to severe gastropathy and prophylaxis may prevent this progression. ${ }^{5}$ Secondly, it has recently been claimed that identification of one particular pattern of mild gastropathy - the mosaic pattern-is highly specific for an underlying portal hypertension

Accepted for publication 2 June 1988 and so may be a valuable indirect approach to the diagnosis of cirrhosis and portal hypertension. ${ }^{8}$ For these reasons there is a need to document objectively mild congestive gastropathy.

Endoscopic gastric biopsy specimens have been reported to show the characteristic mucosal vascular changes in a high proportion of patients thought to have mild gastropathy. ${ }^{15}$ As these biopsies are simple to perform, widely practised, and safe this approach is promising. Before endoscopy can be accepted as a technique for diagnosing congestive gastropathy, however, the specificity of these changes needs to be established.

This study aimed to assess the specificity of mucosal vascular changes in endoscopic gastric biopsy specimens from patients with and without portal hypertension.

\section{Patients and methods}

Three groups of patients were studied: (i) twenty consecutive patients with portal hypertension due to confirmed cirrhosis in 17 and primary biliary cirrhosis in three. Eighteen patients had oesophageal varices at endoscopy, while in two patients portal hypertension was diagnosed by the presence of splenic hilar portosystemic collaterals (table 1); (ii) twenty consecutive Patients with non-cirrhotic liver disease (table 1); (iii) twenty consecutive patients with normal endoscopic specimens who were investigated for dyspepsia. The final diagnosis was non-ulcer dyspepsia or oesophagitis. 
All patients were endoscoped by a single observer (SHS) and visual findings suggestive of gastropathy recorded. Mild gastropathy was recognised by any of the following endoscopic appearances. ${ }^{9}$

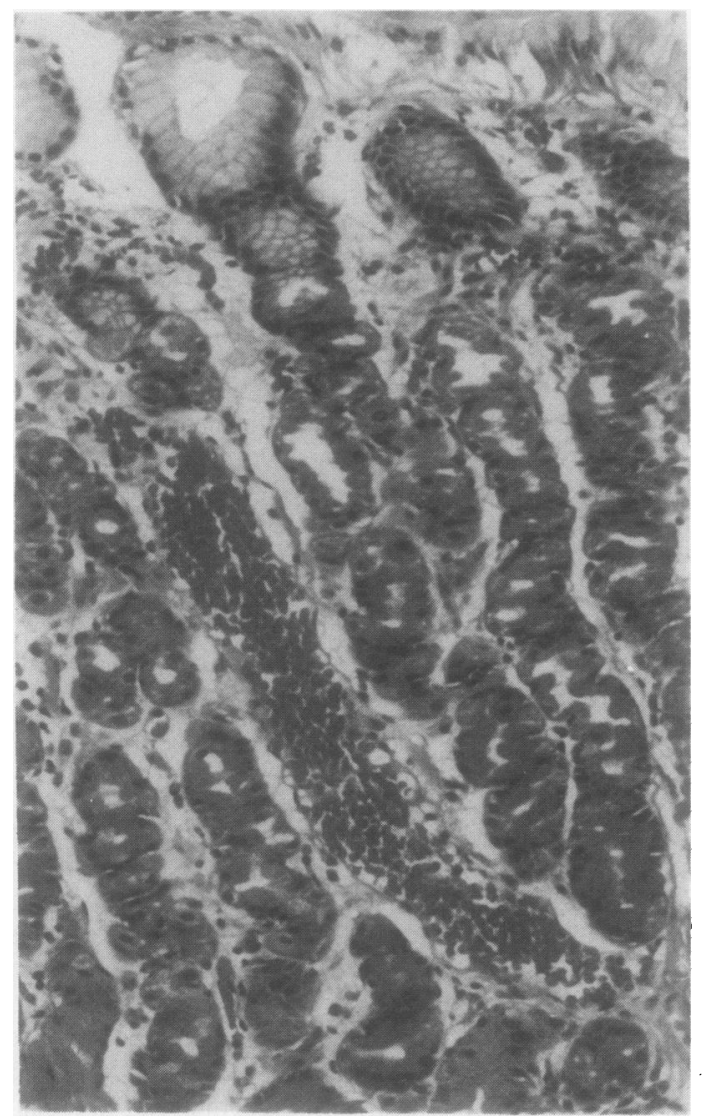

Figure Gastric body biopsy specimen from patient without portal hypertension showing uninflamed gastric mucosa with prominent dilated capillaries. (Haematoxylin and eosin.)

Table 1 Aetiology of liver disease

\begin{tabular}{lr}
\hline Group & No of patients \\
\hline Group $(i)$ : & \\
Alcoholic cirrhosis & 11 \\
Cryptogenic cirrhosis & 2 \\
Primary biliary cirrhosis & 2 \\
Chronic active hepatitis & \\
Group (ii): & 13 \\
Alcoholic liver disease & 2 \\
Primary biliary cirrhosis & 2 \\
Chronic persistent hepatitis & 1 \\
Granulomatous hepatitis & 1 \\
Extrahepatic cholestasis (common bile duct stone) & 1 \\
Non-alcoholic hepatic steatosis &
\end{tabular}

Table 2 Distribution of mucosal vascular changes

\begin{tabular}{|c|c|c|c|}
\hline \multirow[b]{2}{*}{ Biopsy site } & \multicolumn{3}{|c|}{$\begin{array}{l}\text { No of patients with capillary } \\
\text { dilatation }\end{array}$} \\
\hline & $\begin{array}{l}\text { Group (i) } \\
(n=19)\end{array}$ & $\begin{array}{l}\text { Group (ii) } \\
(n=20)\end{array}$ & $\begin{array}{l}\text { Group (iii) } \\
(n=19)\end{array}$ \\
\hline $\begin{array}{l}\text { Antrum } \\
\text { Body } \\
\text { Both body and antrum } \\
\text { Total }\end{array}$ & $\begin{array}{l}6 \\
5 \\
2 \\
9 / 19\end{array}$ & $\begin{array}{c}8 \\
14 \\
5 \\
17 / 20\end{array}$ & $\begin{array}{l}13 \\
12 \\
9 \\
16 / 19\end{array}$ \\
\hline
\end{tabular}

Table 3 Correlation between mucosal capillary dilatation and degree of inflammation

\begin{tabular}{|c|c|c|c|}
\hline \multirow[b]{2}{*}{ Degree of inflammation } & \multicolumn{3}{|c|}{$\begin{array}{l}\text { No of biopsy sites with capillary } \\
\text { dilatation present }\end{array}$} \\
\hline & $\begin{array}{l}\text { Group (i) } \\
(n=38)\end{array}$ & $\begin{array}{l}\text { Group (ii) } \\
(n=37)\end{array}$ & $\begin{array}{l}\text { Group (iii) } \\
(n=37)\end{array}$ \\
\hline \multirow[t]{2}{*}{$\begin{array}{l}\text { Absent } \\
\text { Mild } \\
\text { Moderate } \\
\text { Severe }\end{array}$} & $\begin{array}{l}5 \\
4 \\
2 \\
0\end{array}$ & $\begin{array}{r}16 \\
2 \\
3 \\
1\end{array}$ & $\begin{array}{r}13 \\
9 \\
3 \\
0\end{array}$ \\
\hline & dilatation al & sent: & \\
\hline $\begin{array}{l}\text { Absent } \\
\text { Mild } \\
\text { Moderate } \\
\text { Severe }\end{array}$ & $\begin{array}{r}12 \\
10 \\
4 \\
1\end{array}$ & $\begin{array}{l}8 \\
4 \\
3 \\
0\end{array}$ & $\begin{array}{l}7 \\
4 \\
1 \\
0\end{array}$ \\
\hline
\end{tabular}

1 A fine pink speckling or "scarlatina" type rash. 2 A superficial reddening, particularly on the surface of the rugae giving a striped appearance.

3 A fine white reticular pattern separating areas of raised red oedematous mucosa resembling a "snakeskin".

Two biopsy specimens were taken from the antrum and two from high body on the greater curve. Specimens were fixed in formol saline and stained by haematoxylin and eosin. Coded slides were reviewed by one of us (CMC) without any knowledge of the clinical details.

The following features were assessed: adequacy of the biopsy; vessels-prominence of the mucosal capillaries-whether present (figure); gastritis-type and severity. ${ }^{10}$ Types were classified as superficialactive or chronic; atrophic - active or chronic; and chronic gastritis (unspecified) when inflammation was deep in the mucosa without noticeable gland atrophy. Severity of inflammatory infiltrate was graded as absent, mild, moderate, or severe.

Capillary dilatation was classified as present in a patient if either antrum or body biopsy specimens showed this change. In patients where antrum or body biopsy specimens were too superficial for complete assessment, capillary dilatation were assessed on the specimens from the other site-providing this was adequate (table 2 ). 
The relation between degree of mucosal inflammation and presence of capillary dilatation was analysed for each individual biopsy site (table 3).

Diifferences betwen groups were analysed by $\chi^{2}$ analysis.

\section{Results}

\section{ENDOSCOPY}

Group (i) Endoscopy showed mild gastropathy in 12 of $20(60 \%)$, which in eight patients affected the whole of the stomach, in two cases affecting either the body or antrum alone.

Group (ii) Mild gastropathy was seen in four patients, which in one affected both the body and antrum. In the remaining three cases this affected only the antrum.

Group (iii) None of the patients showed changes of gastropathy.

\section{HISTOLOGY}

Biopsy specimens from eight sites were too superficial for complete assessment and so were excluded from analysis - both antral and body biopsy specimens from a single patient in group (i), two antral and one body biopsy specimen from three patients in group (ii), and both body and antral biopsy specimens from one patient and an antral biopsy specimen from another patient in group (iii).

Group (i) In one patient with endoscopic mild gastropathy, biopsy specimens from both antrum and body were too superficial for complete assessment and this patient was excluded from analysis. Histological analysis showed mucosal capillary dilatation in six of the remaining 11 patients with endoscopic signs of congestive gastropathy. Similar changes were seen in three of eight patients in group (i) with normal endoscopy.

Group (ii) Biopsy specimens were too superficial in three patients in this group with normal endoscopic appearances. In two patients antral biopsy specimens were excluded while in one case the body biopsy specimens were excluded. In these three cases capillary dilatation was assessed from the body or antral biopsy specimens, respectively. Capillary dilatation was seen more often in group (ii) $(17 / 20,85 \%)$ compared with group (i) (nine of 19, 47\%); $\chi^{2}, \mathrm{p}<0.025$ ) (table 2 ). The degree of capillary dilatation in individual biopsy specimens was similar in both groups. Inflammation causing capillary dilatation could not account for these differences as the correlation held even if biopsy specimens showing inflammation were excluded (table 3).

Group (iii) Biopsy specimens from two patients were excluded - both antral and body from one patientand only the antral from another patient. Sixteen of 19
$(84 \%)$ patients showed capillary dilatation. The degree of dilatation was similar to the two other groups. There was no significant differerences between the degree of inflammation in the specimens with capillary dilatation compared with those without capillary dilatation $\left(\chi^{2}=0.632, \mathrm{p}<0.05\right)$.

\section{Discussion}

Gastric resection and necropsy specimens have shown that the most consistent histological feature of severe gastropathy associated with portal hypertension is dilatation and tortuosity of submucosal veins. Mucosal changes such as capillary ectasia can be seen but these may be focal.

The current approach to the diagnosis of mild congestive gastropathy by endoscopic recognition of abnormalities in gastric mucosal appearances is unsatisfactory because it is subjective and therefore liable to observer bias. Endoscopic biopsy specimens are superficial and so limited to assessing the mucosa, but have been used in two studies to support the endoscopic diagnosis of mild congestive gastropathy. In the original series 10 of $14(71 \%)$ of patients with endoscopic mild gastropathy had biopsy changes indicative of mucosal ectasia ${ }^{1}$; in the more recent series $100 \%$ of specimens showed these changes. ${ }^{58}$

In previous studies more than one endoscopist was involved and it was not clear if the histologist could have been biased by prior knowledge of endoscopic appearances. In the present study we minimised observer errors by restricting endoscopic assessment to a single observer and minimised observer bias by blind assessment.

The major finding of this study was the lack of specificity of prominence of the mucosal capillaries for endoscopic mild gastropathy. Indeed, histological changes alleged to correlate with mild congestive gastropathy were seen more often in control patients both in the non-cirrhotic group and the normal endoscopy group. The high incidence of mucosal capillary dilatation in the control groups cannot be attributed to inclusion of examples of less pronounced changes in the biopsy specimens from control groups as the degree of dilatation was as great as in the portal hypertension group.

Mucosal capillary dilatation is known not to be specific for congestive gastropathy. Dixon reported identical changes in reflux gastropathy not caused by inflammation." We specifically assessed the degree of inflammatory change and found that it could not have accounted for the high incidence of capillary dilatation in the control groups.

Our results add to the accumulating evidence that neither endoscopic appearances nor histological assessment of endoscopic biopsy specimens are specific for mild congestive gastropathy. In the 
original study three of nine $(33 \%)$ of patients with portal hypertension were found to have histological features of congestive gastropathy but normal endoscopic appearances. ${ }^{1}$ This is similar to the results of our present study. In a subsequent controlled study assessing the affect of propranolol in congestive gastropathy endoscopic severity correlated poorly with histological analysis of endoscopic biopsy specimens. ${ }^{5}$ In a limited study, however, Papazian et al found capillary dilatation in all seven patients with mosaic congestive gastropathy while none of nine patients without portal hypertension showed this change. ${ }^{8}$ The reason why the results of that study differ from ours is not clear, but it was based on smaller numbers and observer bias may have been present. While submucosal vascular changes seen on surgical or necropsy specimens have been shown to correlate well with severe gastropathy, mucosal vascular ectasia does not correlate well with endoscopic changes suggestive of mild congestive gastropathy. Moreover, these endoscopic appearances themselves seem to be unreliable. Consequently an approach based on endoscopy or endoscopic biopsy to detect or assess mild congestive gastropathy is unsatisfactory. There is a need for an alternative method of documenting mild congestive gastropathy to determine its association with severe congestive gastropathy, to assess the values of prophylaxis, and to determine the specificity for portal hypertension.
References

1 McCormack TT, Sims J, Eyre-Brook I, et al. Gastric lesions in portal hypertension: inflammatory gastritis or congestive gastropathy? Gut 1985;26:1226-32.

2 Dagradi AE, Mehler R, Tan DTD, et al. Sources of upper gastrointestinal bleeding in patients with liver cirrhosis and large oesophageal varices. Am J Gastroenterol 1970;54:458-63.

3 Khodadoost J, Glass GBJ. Erosive gastritis and acute gastroduodenal ulcerations as source of upper gastrointestinal bleeding in liver cirrhosis. Digestion 1972;1:129-38.

4 Waldram $R$, Davis $M$, Nunnerly $H$, et al. Emergency endoscopy after gastrointestinal haemorrhage in 50 patients with portal hypertension. Br Med J 1974;4:94-6.

5 Hosking SW, Kennedy H, Seddon I, Triger DR. The role of propranolol in congestive gastropathy of portal hypertension. Hepatology 1987;7:437-41.

6 Quintero E, Pique J, Bombi JA, et al. Gastric mucosal vascular ectasias causing bleeding in cirrhosis. Gastroenterology 1987;93:1054-61.

7 Schiller KFR, Cockel R, Hunt R. A colour atlas of gastrointestinal endoscopy. London: Chapman and Hall, 1986.

8 Papazian A, Braillon A, Dupas JL, Sevenet F, Capron JP. Portal hypertensive gastric mucosa: an endoscopic study. Gut 1986;27:1199-203.

9 Taor RE, Fox B, Ware J, Johnson AG. Gastritis-gastroscopic and microscopic. Endoscopy 1975;7:209-15.

10 Whitehead R, Trulove SC, Gear MWL. The histological diagnosis of chronic gastritis in fibreoptic gastroscope biopsy specimens. $J$ Clin Pathol 1972;25:1-11.

11 Dixon MF, O'Connor HJ, Axon ATR, King RFG, Johnston D. Reflux gastritis: distinct histopathological entity. J Clin Pathol 1986;39:524-30.

Requests for reprints to: Dr S H Saverymuttu, Department of Medicine II, St George's Hospital Medical School, Cranmer Terrace, London SW17 0RE, England. 